American Journal of Applied Sciences 5 (7): 860-865, 2008

ISSN 1546-9239

(C) 2008 Science Publications

\title{
The Role of $\mathbf{R}$ and $\mathbf{D}$ and Business Performance in Korean Electronics Companies
}

\author{
${ }^{1}$ Woosik Kim and ${ }^{2}$ Seok Yoon \\ ${ }^{1}$ College of Business Administration, Konkuk University, Seoul, 143-701, Korea \\ ${ }^{2}$ Korea National Assembly, 1 Yoido Dong, Young Deung Po-Ku, Seoul, 150-703, Korea
}

\begin{abstract}
This study examines the electronics industry in Korea with two points of view; management activity and research and development ( $\mathrm{R}$ and $\mathrm{D}$ ) activity for reviewing effectiveness and analyzes effects of R and D activity on business performance. The conclusion of the study shows (1) in terms of DEA measurement in order to compare with efficiency of business performance and R and D activity, those enterprises show high efficiency on their business performance record and low efficiency on their R and D activity. Most enterprises tend to have lower efficiency on $\mathrm{R}$ and $\mathrm{D}$ activity than business performance. That is to say, the result is in accord with Hypotheses 1 (H1). (2) In terms of effects of $\mathrm{R}$ and $\mathrm{D}$ activities on business performance, the management activity variable, there is a positive (+) correlation and a statistical significance existed. This result rejects Hypothesis $2(\mathrm{H} 2)$ formulated in this study.
\end{abstract}

Key words: Business performance, efficiency, R and D investment

\section{INTRODUCTION}

One of the goals of economic activity in enterprises is profit maximization. Enterprises make full use of various strategies to maximize their profits. One such strategy is cutting down on expenses by securing raw materials, recruiting superior human resources, introducing new technologies and doing $\mathrm{R}$ and $\mathrm{D}$ activities.

By the way, it is said that $\mathrm{R}$ and $\mathrm{D}$ activities have a positive effect on business performance, which has been supported by the results of empirical studies. Comanor and Scherer ${ }^{[1]}$ studied the correlation among the number of the applications for a patent, the number of researchers and the sale. Branch ${ }^{[2]}$ conducted an empirical study about the effects of the number of the applications for a patent as the result of $\mathrm{R}$ and $\mathrm{D}$ activities on the profit of business and concluded that the $\mathrm{R}$ and $\mathrm{D}$ activities had a positive correlation with the profit of business.

Buzzell, Gale and Sultan ${ }^{[3]}$ also surveyed the rate of $\mathrm{R}$ and $\mathrm{D}$ expenses compared with sales by market share, the part of business performance and it came to the conclusion that the enterprises which had a high occupancy in the market spent more money on R and D expenses. Moreover, Grabowski and Mueller ${ }^{[4]}$ maintained that the expense of $\mathrm{R}$ and $\mathrm{D}$ of the enterprises had a great and consistent influence on maximizing profit. That is to say, the investment for $\mathrm{R}$ and $\mathrm{D}$ now can lead to a positive effect on improving business performance and values in the future covering 3-7 years.

The studies of Lee ${ }^{[5]}$ and Lee and $\mathrm{Kim}^{[6]}$ showed the same conclusion as the previous studies. In other words, generally $\mathrm{R}$ and $\mathrm{D}$ investment can develop the management ability and productivity of the enterprises by introduction and development of new technologies and new products.

This study arose from the one curiosity between $\mathrm{R}$ and $\mathrm{D}$ activities and management activities. It was that various inputs of human resources and expenses for $\mathrm{R}$ and $\mathrm{D}$ were directly proportional to the business performance. Therefore, the aim of this study is to analyze the relationship between $\mathrm{R}$ and $\mathrm{D}$ efficiency and management efficiency, to suggest policies based on the empirical study and to prove that the conclusion of previous studies can be applied in Korea as well.

\section{MATERIALS AND METHODS}

In this study, DEA (Data Envelope Analysis) was conducted to evaluate the efficiency of business performance and $\mathrm{R}$ and $\mathrm{D}$ activities and analyze the effect of $\mathrm{R}$ and $\mathrm{D}$ activities on business performance. First of all, DEA is one of the effective analytical methods for measuring a business performance and efficiency (Sengupta, ${ }^{[\pi]}$. DEA can measure efficiency 
by comparing input and output observed from the legal organization of the enterprise and show relative efficiency by comparing a certain enterprise with others.

By the way, DEA is non-parametric and a relative way to measure efficiency since it doesn't apply equal weight to all the enterprises to measure, but, instead it finds the most favorable weight for each enterprise.

The subjects for DEA in this study were 49 enterprises. In the analysis of management efficiency, 4 inputs and 1 output were used and in the analysis of $R$ and D 4 inputs and 2 outputs were set. According to the setting, the scale of groups comparing to the number of input and output to apply DEA model satisfied the requirement for 3 ways. There are 3 ways to decide scales of a group based on the number of input and output to avoid overestimation of efficiency in applying the DEA model. One is the way to choose the number more than 3 times of the sum of input and output (Banker, Charnes and Cooper) ${ }^{[8]}$. Another is to choose the number more than the multiple of input and output (Boussofiane, Dyson and Thanassoulis) $^{[9]}$. The other is to choose the number more than 2 times of the sum of input and output (Fitzsimmons and Fitzsimmons, $1994)^{[10]}$. This study chose the basic model, DEA/CCR model (Charnes, Cooper and Rhodes) ${ }^{[11]}$.

Next, to analyze business performance, some results were assumed through the multiple regression models which had one dependent variable, business performance and two independent variables, management activities and $\mathrm{R}$ and $\mathrm{D}$ activities. In this process, the correlation between independent variables including a lot of specific management activities and the dependent variable, business performance and the significance of the analysis were ascertained.

Before the analysis, the basic assumptions should have an examining process to apply to the measuring model in multiple regressions. First, if there is a high correlation among independent variables in using transaction data, the problem of multicollinearity can happen. Next, the problem of heteroscedasticity can occur when the error distribution becomes homoscedasticity. If these assumptions are not satisfied, they can't be good estimation (BLUE) because the biases of estimation are able to arise. Therefore, condition index test for multicollinearity and Peason's correlation test for homoscedasticity were conducted.

In this study, the result of heteroscedasticity test showed that the number of $\mathrm{R}$ and $\mathrm{D}$ project outputs (RDO) had significance with the number of patents (NP), dependent variable. So, RDO was excluded in the independent variables. In addition, in a problem of multicollinearity, RDO was excluded in order not to make heteroscedasticity affect the analysis because the condition index of ROD was over 20 . In the test of multicollinearity, the condition index between the number of patents and the number of RDO was 11.767 and 20.632 each, so we could conclude that correlation existed between 2 the variables. Therefore, ROD independent variable was excluded in this study.

Data: In this study, it used the data about the enterprises until 2004 among actual resources from the KOITA Research ${ }^{[12]}$ conducted by the Korea Industrial Technology Association (KOITA) in the Ministry of Science and Technology in Korea, which is annually carried out ranging over the whole area of industry. The Ministry of Science and Technology annually surveys and analyzes the aspect of $\mathrm{R}$ and $\mathrm{D}$ activities of enterprises to reflect data on economic policies and makes a reliable statistical data for all the industrial circles to utilize.

According to this, the applied research data have a strong advantage that they are based on actual research, that is to say, they are very reliable. On the other hand, they don't have a lot of details because the subjects of the survey range over all kinds of enterprises. However, it still includes a lot of data about input and output of management activities and $\mathrm{R}$ and $\mathrm{D}$ activities that this study requires, so the data was utilized.

This data is about enterprises in the electronics industry belonging to 32 nd class in Korean Standard Industrial Classification. The electronics industry has the shortest life cycle among all the industries and usually considers $\mathrm{R}$ and $\mathrm{D}$ investment very important. The Korean electronics industry has been acclaimed as the most competitive and developed industry in the whole Korean manufacturing industries. By the time it got this fame, both large enterprises and medium and small and venture businesses had made an enormous investment in $\mathrm{R}$ and $\mathrm{D}$ activities. Therefore, the Korean electronics industry has been chosen as subjects of this study.

The number of subject enterprises of the research was 3,516 and among them, the number of enterprises in the electronics industry is 102 . Some items are relatively accurate and accessible and then they are chosen as variables. Each variable is as follows; Number of available Workers (NW) and Total Assets (TA) as the management activity variables, number of available $\mathrm{R}$ and $\mathrm{D}$ Workers (RDW), R and D workers Cost (RDC), number of patents achieved inside and outside of the country (NP) and R and D project outputs (RDO) as the R and D activity variables. After that, final actual data related to management and $R$ and $D$ activities of 49 enterprises in the Korean electronics industry has been selected by eliminating unavailable data and errors. However, in multiple regressions, 102 samples of the electronics industry were analyzed. 
Hypothesis: The general idea of $\mathrm{R}$ and $\mathrm{D}$ is that the investment in $\mathrm{R}$ and $\mathrm{D}$ has a positive effect on business performance. In other words, the enterprises that invest more in $\mathrm{R}$ and $\mathrm{D}$ can bolster business performance. By the way, when it comes to efficiency, it is concluded that it is necessary to develop new technologies and products that are competitive in the market to increase the sales and profits of the enterprises. Therefore, enterprises should increase investment in $R$ and $D$ activities to facilitate the development of new technologies and products because the efficiency of management activities can be higher with the increase of the sales and profits once new technologies and products result in success in the market.

On the other hand, too much investment by enterprises in $R$ and $D$ activities can make the efficiency of $R$ and $D$ activities lower because it's hard to estimate and recognize the output scale they will get after their developing new technologies and products. Also, that kind of new technologies and product should be followed with production, sales and after service, so the estimation of the efficiency of the investment is frequently very difficult.

For those reasons, in many cases, the efficiency of $\mathrm{R}$ and $\mathrm{D}$ activities takes on an opposite aspect to that of management efficiency. However the investment in $\mathrm{R}$ and D eventually causes the development of new technologies and competitive products, which can increase the sales and profits. So, we can say that both productivity of the enterprises and efficiency of output increase. On the basis of that fact, 2 hypotheses have been set in this study as follows.

Hypothesis 1 (H1): The efficiency of management activities and the efficiency of $\mathrm{R}$ and $\mathrm{D}$ activities are incompatible.

Hypothesis 2 (H2): R and D variables do not have a significantly positive (+) effect on the business output.

\section{RESULTS}

In Table 1, it shows the result of efficiency of management activities and the efficiency of $\mathrm{R}$ and $\mathrm{D}$ activities of enterprises in the electronics industry about the DEA conducted in this study. The relation between management activities and $\mathrm{R}$ and $\mathrm{D}$ activities is as follows.

First, the rate of enterprises that showed the result that management efficiency was higher than $\mathrm{R}$ and $\mathrm{D}$ efficiency was $72 \%$ and the rate that R and D efficiency was higher than management efficiency was $26 \%$. There was only one Enterprise that showed high efficiency up to 1.0 in both parts and it occupied $2 \%$ in the whole group.

The rate of enterprises that showed the result that management efficiency was extremely higher than $\mathrm{R}$ and $\mathrm{D}$ efficiency more than 0.7 was $16 \%$, while the rate of enterprises that showed the result that $\mathrm{R}$ and $\mathrm{D}$ efficiency was extremely higher than management efficiency more than 0.7 was only $2 \%$.

Table 1: Efficiency of management activities and $\mathrm{R}$ and $\mathrm{D}$ activities of enterprises

\begin{tabular}{|c|c|c|c|c|c|c|c|c|}
\hline $\begin{array}{l}\text { Industry } \\
\text { code }\end{array}$ & $\begin{array}{l}\text { Management } \\
\text { activities }\end{array}$ & $\begin{array}{l}\mathrm{R} \text { and } \mathrm{D} \\
\text { efficiency }\end{array}$ & $\begin{array}{l}\text { Industry } \\
\text { code }\end{array}$ & $\begin{array}{l}\text { Management } \\
\text { activities }\end{array}$ & $\begin{array}{l}\mathrm{R} \text { and } \mathrm{D} \\
\text { efficiency }\end{array}$ & $\begin{array}{l}\text { Industry } \\
\text { code }\end{array}$ & $\begin{array}{l}\text { Management } \\
\text { activities }\end{array}$ & $\begin{array}{l}\text { R and D } \\
\text { efficiency }\end{array}$ \\
\hline$\overline{\mathrm{CA} 01}$ & 19.05 & 4.77 & CC13* & 100.00 & 33.61 & CD15* & 100.00 & 2.99 \\
\hline CB01 & 34.53 & 6.39 & CC14* & 24.70 & 100.00 & CD16* & 40.48 & 5.46 \\
\hline CB02 & 42.97 & 66.77 & CC15* & 41.48 & 0.73 & CD17* & 60.35 & 7.12 \\
\hline CB03 & 42.76 & 50.73 & CD01 & 100.00 & 100.00 & CE01 & 47.03 & 74.52 \\
\hline CB04* & 67.82 & 14.01 & CD02 & 25.28 & 17.79 & CE02 & 33.18 & 2.82 \\
\hline $\mathrm{CC} 01$ & 37.31 & 12.54 & CD03 & 59.60 & 28.68 & CE03* & 47.69 & 7.45 \\
\hline $\mathrm{CC} 02 *$ & 3.63 & 60.22 & CD04 & 50.23 & 18.49 & CE04 & 91.62 & 100.00 \\
\hline $\mathrm{CC} 03$ & 37.75 & 58.58 & CD05 & 44.36 & 28.75 & CE05 & 21.51 & 5.61 \\
\hline $\mathrm{CC} 04$ & 32.00 & 15.03 & CD06* & 100.00 & 9.60 & CE06* & 100.00 & 11.17 \\
\hline $\mathrm{CC} 05$ & 45.93 & 60.61 & CD07 & 44.51 & 16.56 & CE07* & 60.91 & 3.55 \\
\hline CC06 & 74.65 & 73.81 & CD08 & 63.78 & 63.09 & CE08* & 100.00 & 39.85 \\
\hline $\mathrm{CC} 07$ & 58.03 & 74.87 & CD09 & 9.53 & 1.86 & CE09 & 30.93 & 10.71 \\
\hline CC08 & 18.72 & 15.14 & CD10* & 100.00 & 14.14 & CE10* & 100.00 & 25.91 \\
\hline CC09 & 44.40 & 33.16 & CD11* & 38.71 & 100.00 & CE11* & 100.00 & 1.38 \\
\hline CC10* & 100.00 & 4.59 & CD12* & 60.05 & 100.00 & CE12* & 100.00 & 8.62 \\
\hline $\mathrm{CC} 11$ & 35.18 & 0.17 & CD13 & 4.97 & 10.74 & & & \\
\hline $\mathrm{CC} 12^{*}$ & 52.25 & 100.00 & CD14 & 22.26 & 11.57 & & & \\
\hline
\end{tabular}

*: Shows those companies have extremely opposite measurement of Efficiency of Management Activities and R and D activities of enterprises 
Am. J. Applied Sci., 5 (7): 860-865, 2008

Second, when it came to $22 \%$ of enterprises that had high management efficiency up to 1.0, almost every enterprise had a low $\mathrm{R}$ and D efficiency less than 0.40 except 1 enterprise and even half of those had much lower R and D efficiency less than 0.10 .

On the other hand, in case of $13 \%$ of enterprises that had high R and D efficiency up to 1.0 , one third of them also had high management efficiency and another one third had low management efficiency up to around 0.60 and the rest had much lower less than 0.40 .

In conclusion, a lot of enterprises in the electronics industry showed high management efficiency and low $\mathrm{R}$ and $\mathrm{D}$ efficiency and that result is in accord with hypotheses suggested beforehand. Therefore, the conclusion was reached that management efficiency and $\mathrm{R}$ and $\mathrm{D}$ efficiency were incompatible and they had a trade off relationship in industrial situation in Korea.

\section{EMPIRICAL STUDY}

The model: The multiple regressions were conducted to both the management activity variable and the $\mathrm{R}$ and $\mathrm{D}$ activity variable to confirm the previous results about management and $\mathrm{R}$ and $\mathrm{D}$ efficiency more objectively. The multiple regressions let us know whether the management activity variable and the $\mathrm{R}$ and $\mathrm{D}$ activity variable had a correlation to the business performance or not and if so, they also let us know whether it is positive or negative and how significant it is. In these multiple regressions, the sale $(\mathrm{S})$, the business performance variable was set as a dependent variable and the Number of Worker (NW), the Total Asset (TA) and the management activity variables, were set as independent variables. In addition, as the $\mathrm{R}$ and $\mathrm{D}$ activity variables, the number of $\mathrm{R}$ and $\mathrm{D}$ workers (RDW), R and D workers Cost (RDC), number of patents achieved inside and outside of the country (NP) and $\mathrm{R}$ and $\mathrm{D}$ project outputs (RDO) were included in independent variables as the $R$ and $D$ activity variables. The estimated formula of the multiple regressions was as follows.

$$
\begin{aligned}
& \mathrm{S}=\alpha_{\mathrm{o}}+\alpha_{1} \mathrm{NW}+\alpha_{2} \mathrm{TA}+\alpha_{3} \mathrm{RDW}+\alpha_{4} \\
& \mathrm{RDC}+\alpha_{5} \mathrm{NP}+\alpha_{6} \mathrm{RDO}+\mu
\end{aligned}
$$

Where:

Business performance variable S: Sales

Management activity variable NW: Number of workers, TA: Total assets

$\mathrm{R}$ and $\mathrm{D}$ activity variable RDW: $\mathrm{R}$ and $\mathrm{D}$ workers, RDC: $R$ and D costs,

NP: Number of patents,

RDO: Number of R and D project outputs
Table 2: Estimation result of regression model

\begin{tabular}{llll}
\hline $\mathrm{R}$ & $\mathrm{R}^{2}$ & F-value & Significant of F-value \\
\hline 0.856 & 0.734 & 66.768 & 0.000 \\
\hline
\end{tabular}

In Table 2, it shows the result of the multiple regressions. $\mathrm{R}^{2}$, which estimates the significance of the regression model on the result of estimation, was 0.734 and $\mathrm{F}$, which estimates the suitability of the regression model, was 66.768 , so it can be concluded that this estimating model is significant.

The results of this study are as follows. First, between the variable $\mathrm{S}$, the business performance variable and $\mathrm{NW}$, the management activity variable, there was positive (+) correlation and statistical significance existed. However, in case of TA, there was positive correlation between them but statistical significance didn't exist. It was an unexpected result that meant that TA didn't have an influence on the sales in electronics industry.

Second, in the estimation results about $\mathrm{R}$ and $\mathrm{D}$ variables and business performance, both RDW and RDC had a positive $(+)$ correlation and statistical significance existed. It meant that $\mathrm{R}$ and $\mathrm{D}$ activities had an influence on the business performance in the electronics industry and it was the same result as the previous studies of Branch (1974) and Grabowski and Mueller (1978).

Third, the Number of Patents (NP) is positively correlated relationship and statistically significant with the amount of sales (S).

\section{CONCLUDING REMARKS}

On the basis of the results, the results from both the efficiency test by DEA model and the multiple regressions are put together. In the case of the DEA model, $72 \%$ of the enterprises showed results that were in accord with the Hypothesis 1 (H1). In case of multiple regressions, between the business performance variable, the variable $S$ and $R$ and $D$ activity variables such as RDW and RDC, there was a positive (+) correlation and statistical significance existed.

The suggested hypotheses and analyzed estimation results are as follows. First, enterprises should invest in $\mathrm{R}$ and $\mathrm{D}$ activities to increase the sales and profits of the enterprises, so between the efficiency of R and D activities and management efficiency, there is negative (-) correlation

However the investment in $\mathrm{R}$ and $\mathrm{D}$ eventually causes the development of new technologies and competitive products, which can increase the sales and profits. It means enterprises should consider the efficiency of management to improve their business 
Am. J. Applied Sci., 5 (7): 860-865, 2008

Table 3: Regressional coefficient and estimation result

\begin{tabular}{|c|c|c|c|c|c|}
\hline \multirow[b]{2}{*}{ Independent variable } & \multirow[b]{2}{*}{ Coefficient } & \multirow[b]{2}{*}{ t-value } & \multirow[b]{2}{*}{ Significance } & \multicolumn{2}{|c|}{ Multicollinearity test } \\
\hline & & & & Eigenvalue & Condition index \\
\hline Constant & 104353.8 & 0.589 & 0.558 & 2.605 & 1 \\
\hline NW & $397.5 * * *$ & 10.37 & 0 & 1.068 & 1.562 \\
\hline TA & 0 & 0.236 & 0.814 & 0.842 & 1.759 \\
\hline RDW & $-9184.7 * *$ & -2.239 & 0.027 & 0.478 & 2.335 \\
\hline RDC & $86.4^{* * * *}$ & 3.026 & 0.003 & 0.008 & 8.21 \\
\hline RDO & $562.1 * * *$ & 3.833 & 0 & 0.038 & 11.767 \\
\hline
\end{tabular}

In the t-test, $*$ is significant at $10 \%, * *$ at $5 \%$ and $* * *$ at $1 \%$

performance, so they should increase investment in $\mathrm{R}$ and $\mathrm{D}$ to do so, which makes the $\mathrm{R}$ and $\mathrm{D}$ efficiency lower. Therefore there comes an irony. This result is consistent with that of the efficiency test by DEA model and in accord with hypotheses suggested before.

Next, in the estimation to analyze the influence of $\mathrm{R}$ and $\mathrm{D}$ on sales, the final business performance of enterprises, there is a positive (+) correlation between business performance and other $\mathrm{R}$ and $\mathrm{D}$ variables. This result rejects hypothesis 2 formulated in this study.

The final goal of enterprises is the maximization of business performance and to achieve it, they should increase their efficiency by decreasing expenses or increasing output, which leads the incompatibility between $\mathrm{R}$ and $\mathrm{D}$ efficiency and management efficiency. That is, enterprises should invest in R and D activities to increase the sales and management efficiency, so there is negative (-) correlation between the efficiency of $\mathrm{R}$ and $\mathrm{D}$ activities and management efficiency.

However the investment in $\mathrm{R}$ and $\mathrm{D}$ eventually causes the development of new technologies and competitive products, which can increase the sales and profits. So, their productivity and output can be increased by $\mathrm{R}$ and $\mathrm{D}$ investment. It means enterprises should consider the efficiency of management to improve their business performance, so they should increase investment in $\mathrm{R}$ and $\mathrm{D}$ to do so, which makes the R and D efficiency lower. Therefore there comes an irony.

By the way, that kind of ironical result can prove that considering management efficiency is just the part of the process of achieving the final goal, improving business performance. In other words, we can find two ideal ways when considering all the ways to increase management efficiency and achieve the final goal, bolstering business performance. One is to improve the business performance by decreasing expenses and increasing output at the same time and the other is to increase production as much as possible, even though they can't decrease expenses.

Between these two ways, enterprises want to pursue the former one, of course. In the real situation, however, it is very hard to pursue because it has a tradeoff relation, especially in $\mathrm{R}$ and $\mathrm{D}$ investment that requires huge expenses. So, the possible way in the real situation is the latter. They should invest in $\mathrm{R}$ and $\mathrm{D}$ despite enormous expenses after they come to the conclusion that the investment leads to more sales and profits in the end. It means that $\mathrm{R}$ and $\mathrm{D}$ investment should go ahead before achieving the promotion of business performance. Even though that kind of investment can lead to temporal decline of management efficiency, it is inevitable in that we should consider long term management. It is similar to make body smaller temporally to prepare for a further or higher jump. Therefore, enterprises should increase investment in developing new technologies and products that are superior and competitive in the market to maximize management efficiency and output ultimately, accepting the lower R and D efficiency.

Finally, this study has significance for estimating the relation between management and $\mathrm{R}$ and $\mathrm{D}$ on the view of relative efficiency. However, it also has a limitation that there were not enough samples and the analysis was conducted only for enterprises in the electronics industry in Korea. In consequence, the following studies are required that can acquire more objectivity by enlarging the number of samples and ranges of study.

Appendix A. Results of correlation test

\begin{tabular}{llccccc}
\hline & NW & TA & RDW & RDC & NP & RDO \\
\hline NW & 1.000 & .407 & .477 & .533 & .497 & $.715^{*}$ \\
& $()$. & $(.000)$ & $(.000)$ & $(.000)$ & $(.001)$ & $(.460)$ \\
TA & 1.000 & .376 & .392 & .384 & .620 & \\
& $()$. & $(.000)$ & $(.000)$ & $(.000)$ & $(.447)$ & \\
RDW & 1.000 & .377 & .471 & .625 & & \\
& $()$. & $(.000)$ & $(.000)$ & $(.432)$ & & \\
RDC & 1.000 & .230 & .627 & & & \\
& $()$. & $(.000)$ & $(.426)$ & & & \\
NP & 1.000 & $.813^{*}$ & & & & \\
& $()$. & $(.520)$ & & & & \\
RDO & 1.000 & & & & & \\
& $()$. & & & & & \\
\hline
\end{tabular}

*: $\mathrm{p}>0.1$, the others are $\mathrm{p}<0.01$ or $\mathrm{p}<0.05$ 


\section{REFERENCES}

1. Comanor, W.S. and F.M. Scherer, 1969. Patent statistics as a measure of technology change. J. Politic. Econ., 77 (3): 392-398.

2. Branch, B., 1974. R and D activity and profitability: A distributed lag analysis. J. Politic. Econ., 82 (51): 999-1011.

3. Buzzell, R.D., B.T. Gale and R.G. Sultan, 1975. Market share-a key to profitability. Harvard Business Rev., 1: 1-9.

4. Grabowski, H. and D. Mueller, 1978. Industrial research and development, intangibles capital stock and firm profit rates. Bell. J. Econ., 9: 328-343.

5. Lee, K.C., 1991. The impact of $\mathrm{R}$ and $\mathrm{D}$ expenditures on productivity increase in Korean manufacturing companies. Ph.D. Thesis, Seoul National University, Korea.

6. Lee, D.L. and K.M. Hwan, 2002. A study on the influence of $\mathrm{R}$ and $\mathrm{D}$ expenditure on firm's growth rate. J. Taxat. Account., 3 (1): 5-31.
7. Sengupta, J.K., 1995. Dynamics of data envelopment analysis, Theory of systems efficiency. Kluwer Acad. Publ., 38 (85): 691-702.

8. Banker, R.D., A. Charnes and W.W. Cooper, 1984. Some models for estimating technical and scale inefficiencies in data envelopment analysis. Manage. Sci., 30 (9): 1078-1092.

9. Boussofiane, A., R.G. Dyson and E. Thanassoulis, 1991. Applied data envelopment analysis. Eur. J. Operat. Res., 32: 1-15.

10. Fitzsimmons, J.A. and M.J. Fitzsimmons, 1994. Service Management for Competitive Advantage. New York: McGraw-Hill Inc., pp: 391-462.

11. Charnes, A., W.W. Cooper and E. Rhodes, 1978. Measuring the efficiency of decision making units. Eur. J. Operat. Res., 2: 429-444.

12. Korea Industrial Technology Association 2004. KOITA Research. 2005.2. 